\title{
Problems and Countermeasures of rural water ecological civilization construction under river system
}

\author{
Min Xiang 1,a, ${ }^{*}$, Yan-wen Shi ${ }^{1, b}$, Wei-liang Li ${ }^{1, c}$, Yi-ming Zhou ${ }^{1, d}$, Zheng-jia \\ $\mathrm{GU}^{2, \mathrm{e}}$
}

${ }^{1}$ School of Business Administration of Hohai University, Changzhou 213022, Jiangsu

China: ${ }^{2}$ College of Mechanical and Electrical Engineering of Hohai University, Changzhou 213022, Jiangsu China

a1371642393@qq.com, ${ }^{b} 1347865924 @ q q . c o m,{ }^{c 237559927 @ q q . c o m ~}$

${ }^{*}$ Corresponding author

Keywords: River chief system; rural; water-ecology environment

\begin{abstract}
Rural water environment is an integral part of the construction of rural water ecological ci vilization and an important part of the construction of "beautiful countryside".But in recent years, ru ral water ecological environment is deteriorating.This paper analyzes the present situation and causes of rural water ecological pollution.

And put forward some concrete suggestions and countermeasures in this paper, such as controlling the sources of pollution, combining with various pollution control technologies, and enhancing the awareness of environmental protection.
\end{abstract}

\section{Introduction}

In recent years, with the acceleration of rural economic construction and the continuous promotion of rural urbanization, water pollution in rural areas is becoming increasingly serious. At present, non-point source pollution of rural water environment presents a wide range of pollution, a variety of pollutants, non-point source pollution monitoring, management, control difficulties and other characteristics. Rural water pollution not only affects grain production and the economic income of rural residents, but also endangers the lives and health of villagers. According to the survey, $88 \%$ of the sick population and $33 \%$ of the deaths in China are directly related to the unclean use of domestic water[1].At the same time, due to the characteristics of large quantity, wide distribution and low grade of river courses in rural China, and the influence of local topography, local management policies, local farmers' production and lifestyle, it is difficult to control the water ecology, the heavy work of river management and protection, and the long-term guarantee mechanism of water ecological environment system management. Construction is difficult.

The river length system is an innovative system with unified leadership, clear responsibilities and multi sector cooperation in river management. However, most of the current studies on the ecological environment management of river-length sewage remain at the level of system and theory, and the perspective of subject research is too narrow, lacking of systematicness and integrity. Therefore, on the basis of river-length system, rural water ecological environment management should be based on a comprehensive overall planning from the perspective of systematic thinking. According to the integrity, systematicness and inherent law of the ecosystem, the various elements of the water ecological system, the departments of water ecological management and the different administrative regions within the river basin and within the region should be considered as a whole, and then the construction should be carried out. Systematic water ecological environment governance system, so as to achieve overall protection, system restoration, comprehensive management. Establish a long-term guarantee mechanism for the management of rural water ecological environment system under river-length system to promote the sustainable development of rural economy, society and ecology. 


\section{Present situation of rural water ecological environment pollution}

\subsection{Water pollution caused by domestic sewage}

Because of the vast land in rural areas, rural residents live scattered, there is no sewage collection and treatment system. And the rural villagers were influenced by the traditional way of life and production,and their awareness of the protection of the water ecological environment was insufficient, resulting in that their domestic sewage was directly through self-built drainage ditches thrown into the nearby river or farmland. And in recent years, the rural economic construction has made remarkable achievements, and the living standards of farmers continue to improve. While the population increases, domestic sewage discharge is also increasing. As a result, the pollution rate of water body in rural areas is much faster than the self-purification rate of water body. Black, dirty and odorous water body appears, and the groundwater is polluted through soil infiltration into groundwater. If the water environmental pollution in rural areas can not be effectively controlled and controlled for a long time, it will seriously affect the safety of agricultural and domestic water use of rural residents, thus aggravating the water shortage .

\subsection{Water pollution caused by Agricultural Sewage}

In the process of agricultural production in rural areas, in order to obtain better economic returns, farmers irrationally use a large number of pesticides and fertilizers. According to relevant statistical data, China's pesticide use in 2015 is nearly 1.7 million tons, twice as much as that in 2000.The use of pesticides and fertilizers per unit area increased from $7.66 \mathrm{~kg} / \mathrm{hm} 2$ in 2000 to $13.33 \mathrm{~kg} / \mathrm{hm} 2$ in 2015. The use of fertilizers and pesticides per unit area of cultivated land in developed countries was only about $7 \mathrm{~kg} / \mathrm{hm} 2$. But in fact, the use efficiency of chemical fertilizers and pesticides is not high in China. From the relevant unclear statistical results, the utilization rate of chemical fertilizers and pesticides is only about $20 \%-30 \%$ with the other basic volatilization to the soil and air, and the farmland soil and water environment in rural areas caused serious pollution and destruction[3].In addition, pesticides and fertilizers contain a lot of phosphorus. With the pesticides and fertilizers which are not used by crops entering rivers through drainage ditches or infiltrating into soil and then into groundwater, it is easy to cause eutrophication of water bodies and further worsen the rural water environment.

\subsection{Water pollution caused by industrial sewage}

Due to the transfer of urban industry to rural areas, a large number of industrial wastewater has brought enormous pressure to the rural water ecological environment. At the same time, as to the carrier of rural economic construction, the development of rural enterprises has not only greatly improved the living standards of farmers, but also caused serious pollution of rural water ecological environment. At present, the development of township enterprises is generally characterized by scattered distribution, small scale, extensive management and backward production technology [3], especially in some township paper mills, printing plants, chemical plants, etc. Because of the imperfect infrastructure, the weak sense of corporate social responsibility and the weak awareness of environmental protection, the wastewater from enterprises is discharged without treatment or when the treated wastewater is not up to the standard. Sewage flows into nearby rivers, lakes or farmlands, which have a serious impact on the surrounding farmland and farmers' domestic water use.

\subsection{Water pollution caused by aquaculture sewage}

According to the relevant data of China's livestock and poultry breeding industry in 2015, the pig slaughter is 620 million 357 thousand, the cattle slaughter is 45 million 695 thousand, and the sheep's output is 305 million 705 thousand. According to the calculation of excretion coefficient, the output of livestock and poultry excreta in China in 2015 was 18.96 .773 million tons, BOD 32.773 million tons, COD 39.317 million tons, NH3-N 3.744 million tons, TN 9.122 million tons, and TP 1.949 million tons[2].In livestock and poultry excreta, there are a lot of phosphides and nitrides, such as they enter the water environment, which will cause water pollution, eutrophication, 
and lead to cyanobacteria and other aquatic plants crazy and large-scale growth. The crazy plantsthen cover large areas of water, obstructing the flow of oxygen and carbon dioxide in water and air. Tong, leading to the death of aquatic organisms, such as fish, due to lack of oxygen, thereby affecting the speed of water flow, and even cause "stagnant water".

\section{Rural water ecological environment pollution control countermeasures}

\subsection{Control pollution sources}

In order to control the rural water pollution, we must solve the problem concerning the source of pollutants from the root, and firmly control the source of pollution,and adopt a systematic and integrated management model, and step by step to solve the pollution. At present, the main sources of pollution in rural areas are the excrement discharge of livestock and poultry and the substandard of various sewage.Planning the sewers and drainage ditches of each village as a whole, collecting sewage and excrement systematically, and then adopting centralized treatment. At the same time, we should vigorously promote high-efficiency, low-residue pesticides, improve the utilization of pesticides, reduce pesticide pollution to soil and water quality.

\subsection{Combined with various pollution control technologies}

Due to the scattered geographical location of rural residential areas and rural enterprises, rural water environment management should adopt a variety of models.For industrial waste water with relatively less chemical substance, physical treatment can be adopted. First, the suspended solid pollutants in the sewage can be removed by BOD, and then the colloidal and dissolved organic pollutants in the sewage can be removed. Biological denitrification and phosphorus removal, coagulation and sedimentation, sand rate, activated carbon adsorption and ion exchange can be used to remove pollutants from livestock manur, agricultural sewage and domestic sewage containing more phosphorus, nitrogen and its compounds. For the scattered residential areas where the sewage is difficult to collect, the courtyard type constructed wetland treatment technology can be adopted. Combining with the local landforms and landforms, we can simulate a more complete and fluent ecological system by feeding fish and shrimp, planting aquatic plants such as bittergrass, tobacco and Elodea, and using animals, plants and microorganisms to achieve green pollution control. The treated water will be used for two times, such as aquaculture and irrigation.

\subsection{Enhance environmental awareness}

Because of the long-term influence of traditional ideas and low cultural level, the villagers are not aware of the environmental protection of water resources. Even think that it is the government's responsibility to control sewage, promote environmental protection and other issues, villagers are more inclined to pay attention to their economic interests. In this regard, on the one hand, the government should strengthen the publicity of villagers' water environmental protection by using posters, television, network and other media, and regularly convene villagers' seminars, lectures, etc. to carry out environmental protection publicity, while promoting some energy-saving technologies and high-efficiency low-phosphorus pesticides, training knowledge of green farming, planting, irrigation and so on.On the other hand, we should strengthen the training of environmental knowledge of rural leaders. We should persist in training rural cadres, urge them to learn environmental protection knowledge and technology, and strengthen their awareness of environmental governance. Only when they attach importance to ecological civilization can they better lead peasants to the road of jointing pollution prevention and pollution control.

\section{Acknowledgement}

This research was financially supported by the National University Student Innovation Project for Hohai University(Grant NO. 201810294081) and the Provincial University Student Innovation Project for Hohai University (Grant NO.201810294086X). 


\section{Reference}

[1] Jiang Feng. Study on the Present Situation, Causes and Countermeasures of Rural Water Pollution [J]. Resource Conservation and Environmental Protection, 2017 (05): $19+23$.

[2] $\mathrm{Xu}$ Jiahui.Analysis of the present situation and Countermeasures of rural ecological environment management[J].Journal of the Party School of the Chengdu Municipal Party Committee of the Communist Party of China, 2017 (06): 73-76.

[3] Shi Youping. Difficulties and Countermeasures in the practice of "river length system" [D]. Nanjing University, 2018. 